\title{
Impact of land use/land cover change on changes in surface solar radiation in eastern China since the reform and opening up
}

\author{
Cheng Qian
}

Received: 28 April 2014 / Accepted: 8 December 2014 / Published online: 24 December 2014

(C) The Author(s) 2014. This article is published with open access at Springerlink.com

\begin{abstract}
Observational evidence of the impacts of land use/land cover change (LULCC) on changes in surface solar radiation (SSR) in eastern China (EC) during 1979-2008 are identified by using diurnal temperature range as a proxy of SSR and by using observation minus reanalysis approach to disentangle these effects. For the period 1979-2008, the impact of LULCC is shown as a reduction in SSR in most stations in EC, whereas SSR in the reanalysis data has increased at nearly every location. The competition of the dimming effect of LULCC with the brightening effect in the reanalysis results in an observed dipole pattern of SSR with slightly decreasing (increasing) trends in most stations north (south) of the Yangtze River and statistically significant decreasing trends in central EC. In terms of EC area mean, this competition has resulted in a slightly dimming trend in the observed SSR during 19792008, although a transition from an apparent dimming to a general leveling off near 1990 is identified. For the period 1990-2008, LULCC has significantly reduced SSR in central EC and southern China. This dimming effect of LULCC competes with the apparent brightening effect in the reanalysis to result in the general leveling off in the observed SSR in terms of EC area mean and a sandwich spatial pattern in the observed SSR in EC where parts of central EC show significant dimming. The impact of LULCC on the changes in SSR may be through both biogeophysical and biogeochemical processes.
\end{abstract}

\section{Qian $(\triangle)$}

Key Laboratory of Regional Climate-Environment for Temperate East Asia, Institute of Atmospheric Physics, Chinese Academy of Sciences, P. O. Box 9804, Beijing 100029, China

e-mail: qianch@tea.ac.cn

\section{Introduction}

Solar radiation that reaches the land surface, known as surface solar radiation (SSR), is a major component of the surface energy balance and governs a large number of diverse surface processes (Wild 2009a). A key regulator of climate, SSR is also known as global solar radiation, surface insolation, or surface downward solar/shortwave irradiance, which is the sum of the direct and diffuse solar radiation.

SSR has not been constant on the decadal time scale and has shown significant variations, from decreasing to increasing, which is referred to as "from global dimming to brightening" (Wild et al. 2005; Wild 2009a). The origin of the decadal variations in SSR has been suggested to be internal variations in the transparency of the atmosphere, depending on changing characteristics of clouds, aerosols, and radiatively active gases such as water vapor (Wild 2009a, 2012), rather than external forcing by the sun, which shows change during this period of at least an order of magnitude smaller than SSR (Willson and Mordvinov 2003).

In China, a decadal transition in SSR from dimming to brightening or at least a leveling off after approximately 1990 has also been reported (e.g., Liu et al. 2004; Che et al. 2005; Qian et al. 2007, 2011a; Shi et al. 2008; Tang et al. 2011). Changes in clouds cannot explain the dimming because more cloud-free sky has been observed (Qian et al. 2006). The transition can be seen more distinctly when the radiative effects of cloud cover variability is removed (Allen et al. 2013). Several studies have suggested that the increasing emissions of anthropogenic aerosols have resulted in less solar radiation reaching the ground (Che et al. 2005; Qian et al. 2006, 2007; Shi et al. 2008; Wild 2009a). Moreover, researchers have suggested that changes in fuel utilization (Streets et al. 2008) and, thus, in anthropogenic aerosol composition and associated single-scattering albedo (Qian et al. 
2007) may be responsible for the observed transition in SSR (Wild 2009a). Global interests have been paid to the transition in China, particularly the leveling off period when the USA, Europe, and Japan have reported brightening trends, whereas China has experienced neither apparent brightening nor dimming (Wild 2012; Allen et al. 2013). Therefore, this topic deserves additional research from different perspectives.

Since late 1978, China has undergone a reform and opening-up process that has dramatically changed land use/ land cover, particularly for the urbanization process. Land use/ land cover change (LULCC) is an important regional climate forcing that can largely influence the regional surface energy balance (Mahmood et al. 2010; Pielke et al. 2011). In terms of shortwave radiation, LULCC can change outgoing/reflected shortwave radiation and absorbed shortwave radiation by changing land surface albedo. However, it remains unclear whether LULCC can change the incoming shortwave radiation reaching the land surface, i.e., SSR, and this topic has not been discussed in recent reviews of changes in SSR (Wild 2009a, 2012), although it has been pointed out that urbanization effect may affect SSR because radiation sites are often located in urbanized areas (Alpert et al. 2005; Alpert and Kishcha 2008).

In this study, observational evidence of the impact of LULCC on changes in SSR in China during 1979-2008 is presented. The diurnal temperature range (DTR), which is the difference between daily maximum (Tmax) and minimum temperature (Tmin) $2 \mathrm{~m}$ above the surface, is used as a proxy for SSR. This proxy has good prospects (Wild 2009a) because the DTR allows the separation of solar and thermal radiative influences, which affect the DTR in different ways (e.g., Bristow and Campbell 1984). Tmax contains both solar influence and thermal long-wave radiative influences; and the solar flux is obviously only present during daytime, it affects the daily Tmax more than the daily Tmin. The nighttime Tmin, on the contrary, is mainly controlled by thermal radiative exchanges. Thus, Tmax minus Tmin (the DTR), to a considerable extent, eliminates thermal effects from the records, leaving the solar influence as a major forcing factor of DTR. Indeed, several studies have already demonstrated a high correlation of observed SSR and DTR in China (e.g., Liu et al. 2004; Qian et al. 2011a). The temporal correlation coefficient has reached 0.88 in terms of annual mean during 1955-2000 (Liu et al. 2004) and during 1961-2007 (Qian et al. 2011a). In addition, the spatial pattern of the DTR trend is also similar to the downward SSR trend (Fig. 1). Therefore, the DTR is a good proxy of SSR in both temporal and spatial scales and is widely used (e.g., Wild 2009b; Wang and Dickinson 2013). Compared with direct SSR measurements, the advantage of DTR is that it is measured globally with a network of much higher density and earlier records (Wild 2009a). Because only 122 stations measure SSR in China, the DTR proxy can help to fill the gaps in the temporal and spatial distribution of SSR observations. Although the impacts of LULCC on DTR or its changes have been studied in many previous studies (e.g., Gallo et al. 1996; Kalnay and Cai 2003; Hu et al. 2010; Hua and Chen 2013), among these studies few have considered DTR as a proxy of SSR. Since there are few available LULCC datasets with annual resolution currently, especially before 1980 s, I use the observation minus reanalysis (OMR) approach proposed by Kalnay and Cai (2003) to disentangle the impact of LULCC from observed changes in DTR. The basic concept of the OMR method is that the NCEP/NCAR reanalysis data have not well assimilated the surface processes because surface observations of temperature, moisture, and wind over land are not used (Kalnay and Cai 2003; Kistler et al. 2001); however, the reanalysis data do assimilate atmospheric temperatures and other observations that are affected by greenhouse gases and volcanic aerosols (Cai and Kalnay 2004). Therefore, OMR is believed to be attributable primarily to urbanization and other changes in land use (Kalnay and Cai 2003). These effects include not only urbanization effects but also changes in agricultural practices, such as irrigation and deforestation, in addition to those of near-surface aerosols and precipitation associated with urbanization and industrialization (Kalnay et al. 2006). These factors are all parts of LULCC, either as biogeophysical or biogeochemical processes.

The rest of the paper is organized as follows. Section 2 describes the data and methods used, and the research domain
Fig. 1 Linear trends in a annual R-2 downward solar radiation flux at the surface and b R-2 diurnal temperature range for the period 1979-2008. In a, the units are $\mathrm{W} \mathrm{m}^{-2}$ decade $^{-1}$; in $\mathbf{b}$, the units are ${ }^{\circ} \mathrm{C}$ decade ${ }^{-1}$ (a) Downward surface solar radiation

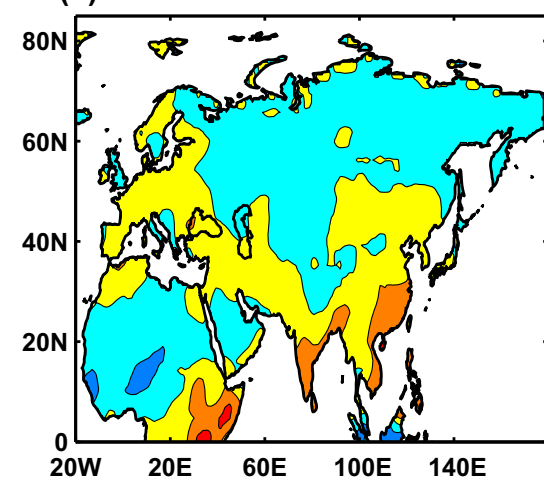

(b) Diurnal temperature range
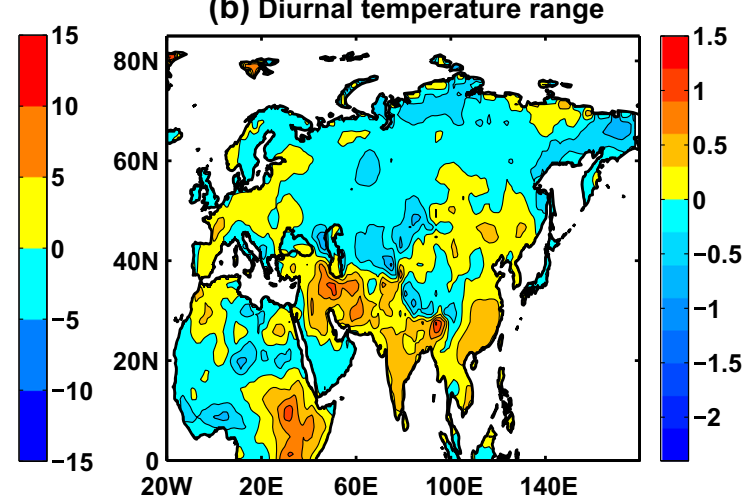
of this study is illustrated. Results for trends in 1979-2008 and 1990-2008 and the impact of LUCC on SSR during these periods are presented. A discussion is given in Section 4, followed by conclusions in Section 5 .

\section{Data and methods}

Observational data used here are homogenized daily Tmax and Tmin datasets (Li and Yan 2009) based on 549 meteorological stations scattered across China for the period 19792008. In these datasets, most of the non-climatic local biases, such biases due to changes in meteorological station location and observational protocols, have been adjusted ( $\mathrm{Li}$ and Yan 2009). Reanalysis data used are National Centers for Environmental Prediction/Department of Energy (NCEP/DOE) Atmospheric Model Intercomparison Project (AMIP)-II reanalysis, hereafter referred to as R-2 (Kanamitsu et al. 2002), for the period 1979-2008. Note that the OMR method proposed by Kalnay and Cai (2003) is based on the assumption that surface observations are not being used in the reanalysis; therefore, not all reanalysis datasets are suitable using this method. R-2 is designed to improve upon the NCEP/NCAR reanalysis, which is used in Kalnay and Cai (2003), by fixing the errors and by updating the parameterizations of the physical processes. R-2 is believed to more accurately characterize soil moisture, clouds, and near-surface temperature over land (Kanamitsu et al. 2002) than NCEP/NCAR reanalysis and has been used to estimate the urbanization effect in South China (Zhou et al. 2004). Data used from R-2 include the daily Tmax and Tmin at $2 \mathrm{~m}$, monthly downward solar radiation flux at the surface (hereafter referred to as downward SSR), and monthly total cloud cover at entire atmosphere considered as a single layer. They are all T62 Gaussian grid with $192 \times 94$ gridpoints.

R-2 data were linearly interpolated to each meteorological station. DTR was calculated on the basis of daily Tmax minus Tmin. To address the leap year, we used the same scheme as that used by Qian et al. (2011b) in which we removed the value for 29 February and replaced the value for 28 February with the average value for 28 and 29 February. Therefore, the effect of the leap year has been considered, and the number of days in each year is always 365 , facilitating the subsequent metric analysis. Temperature anomalies were then computed with respect to the 30-year monthly mean annual cycle for each station and each dataset as done in the data of Kalnay and Cai (2003) to avoid the systematic differences between the reanalysis and observations. Correlation coefficients were calculated between monthly/pentad observational and R-2 anomalies (Fig. 2). Monthly correlation is used mainly to
Fig. 2 Correlation coefficients between observed and R-2 temperature anomalies for the period 1979-2008. The upper (bottom) row shows Tmax (Tmin) anomalies, and the left (right) column shows monthly (pentad) anomalies. The dashed lines indicate $105^{\circ} \mathrm{E}$ (a)

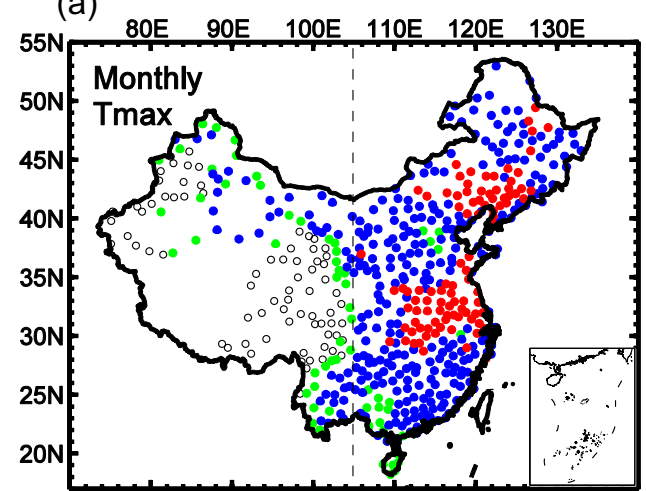

(c)

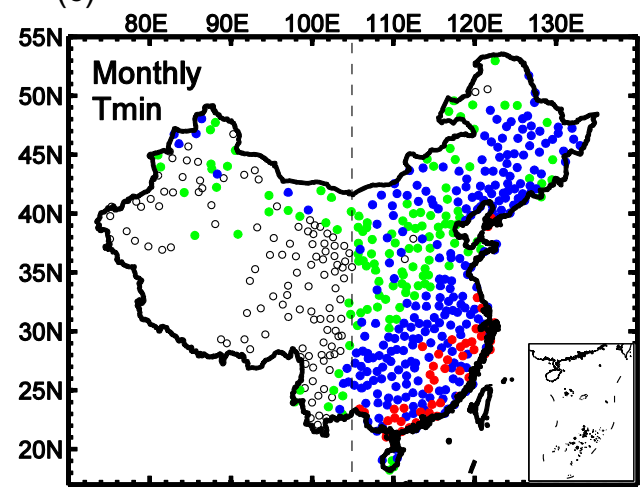

$\circ<0.7 \bullet 0.7-0.8$ (b)

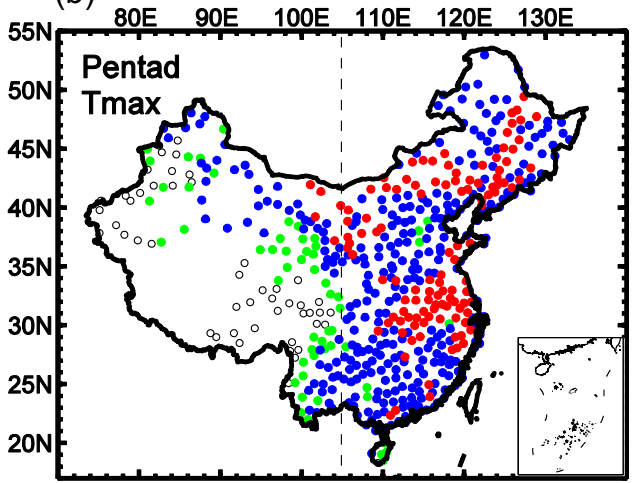

(d)

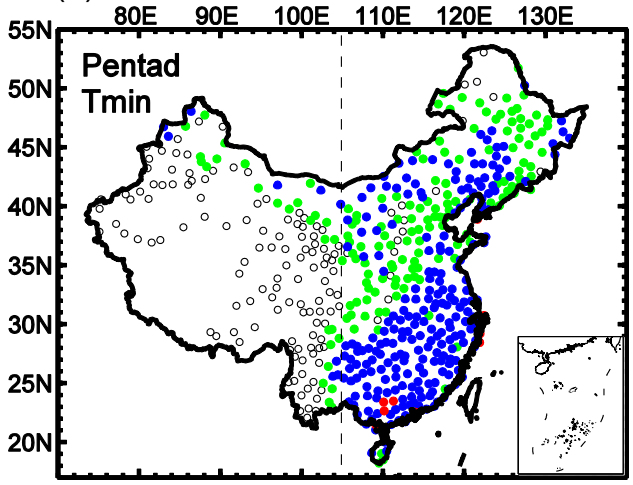

$\bullet 0.8-0.9 \bullet 0.9$ 
see whether reanalysis can well capture the interannual and interdecadal variability. Pentad correlation is used mainly to see whether reanalysis can well capture the weather process, the 10-20-day biweekly oscillation and 30-60-day intraseasonal oscillation. Most parts of eastern China are controlled by the East Asian monsoon; these variablilities are related to rainfall in summer (e.g,. Ju et al. 2005) and thus affect the SSR and temperature. When both monthly and pentad correlations are high, then the reanalysis captures well surface temperature variations caused by atmospheric activities, leaving OMR trend primarily from the impact of LULCC. On the basis of these correlation coefficients, we checked the reliability of R-2 in China and selected the target region as east of $105^{\circ} \mathrm{E}$ because the majority of stations in this region have monthly/ pentad correlation coefficients exceeding 0.7 . In addition to this criterion, the following criteria were also used to select stations: (1) elevation must be below $500 \mathrm{~m}$ to avoid vertical extrapolation errors that may be introduced (Kalnay and Cai 2003), and (2) the correlation coefficients for monthly/pentad Tmax and Tmin all exceeded 0.7. These three criteria resulted in selection of 277 stations (Fig. 3), which evenly covers the majority of eastern China.

The linear trend at each station was estimated by using the ordinary least squares method, and the significance was assessed by using the Mann-Kendall test. In addition, we used the adaptive and temporally local data analysis tool of ensemble empirical mode decomposition (EEMD; Wu and Huang 2009; Huang and $\mathrm{Wu} 2008$ ) method to reveal the nonlinear trend (Wu et al. 2007) in the area mean time series, which is the last component of EEMD result, to identify the evolution of trend (Fig. 4). EEMD has been demonstrated powerful in handling nonlinear and nonstationary climate data (e.g., Wu and Huang 2009; Qian et al. 2009a, 2011a; Wu et al. 2011).

\section{Results}

\subsection{Trends in 1979-2008}

In our research domain (Fig. 3), more than $90 \%$ (more than half) of stations have a correlation coefficient between observation and R-2 for Tmax (Tmin) exceeding 0.8 (Fig. 2), which indicates that R-2 effectively captured the intraseasonal and interannual variability of the observations. However, the correlation coefficients for Tmax are generally larger than those for Tmin, indicating that R-2 to some extent do not well assimilate the surface information, particularly that related to urban conditions because the urbanization effect is observed more apparently in Tmin (e.g., Li et al. 2010; Ren and Zhou 2014). Therefore, the OMR trend should primarily reflect the impact of urbanization and other changes in land use, as was proposed by Kalnay and Cai (2003).
The observed Tmax for the period 1979-2008 increases at all stations in our research area (Fig. 3a), most of which are statistically significant with the largest warming mostly in the lower reaches of the Yangtze River. In the meanwhile, the observed Tmin at nearly all stations shows significant increases with faster rates in northeastern China and much faster rates in North China Plain than those of Tmax (Fig. 3b), resulting in a slight and insignificant decreasing trend in DTR in northeastern China and a significant decreasing trend in DTR in North China Plain (Fig. 3c). In southern China, south of the Yangtze River, there are 123 stations and the warming rates in the Tmax (Fig. 3a) are generally slightly faster than those in the Tmin (Fig. 3b), resulting in a slight and insignificant increasing trend in the DTR at most stations (Fig. 3c). Compared with observation, R-2 (Fig. 3d-f) shows more spatially coherent characteristics, with trends in Tmax, Tmin, and DTR increasing at nearly all stations except for several in northeastern China showing slightly decreasing DTR trends (Fig. 3f). The significant increasing trend in R-2 SSR, as reflected by both DTR (Figs. $3 \mathrm{f}$ and $1 \mathrm{~b}$ ) and downward SSR (Fig. 1a), in southern China induces a significant warming trend in R-2 Tmax because the solar flux is obviously only present during daylight; thus, it affects Tmax more than Tmin. Figure $3 \mathrm{~g}-\mathrm{i}$ reveals that for the majority of stations in the research area, OMR trends cool the Tmax (Fig. 3g) by significantly reducing SSR at nearly all stations, as reflected by DTR (Fig. 3i), whereas they warm the Tmin, particularly in North China Plain with a magnitude of $0.3-0.6^{\circ} \mathrm{C}$ decade $^{-1}$ (Fig. 3h). Because the OMR trends can be attributed primarily to urbanization and other changes in land use, as indicated by Kalnay and Cai (2003), the effects of LULCC are reducing SSR at nearly all stations thus restraining Tmax and increasing Tmin at least in our research area for the period 1979-2008.

In terms of eastern China area mean (Table 1), the observed and R-2 annual Tmax both show significant warming for the period 1979-2008, with R-2 warming faster than the observation. The effect of LULCC significantly cools the Tmax by $0.122{ }^{\circ} \mathrm{C}$ decade ${ }^{-1}$. Moreover, the observed, R-2, and OMR annual Tmin all show significant warming, with the observation warming faster than R-2. The effect of LULCC significantly warms the Tmin by $0.189^{\circ} \mathrm{C}$ decade ${ }^{-1}$, which explains $37.9 \%$ of the observed Tmin trend and is close to the estimation reported by $\mathrm{Hu}$ et al. (2010).

For the area mean changes in SSR in our research domain, Fig. 4 shows that the observed SSR, as indicated by DTR, slightly decreases for the entire 30 years, although the results are not significant (Table 1). The EEMD nonlinear trend further reveals that the SSR undergoes a transition from a decreasing trend to general leveling off in approximately 1990. The linear trend in DTR is $-0.328{ }^{\circ} \mathrm{C}$ decade $^{-1}$ for the period 1979-1989 and $0.008{ }^{\circ} \mathrm{C}$ decade ${ }^{-1}$ for the period 1990-2008. This result is consistent with the solar dimming to "brightening" (a leveling off) transition phenomenon based 

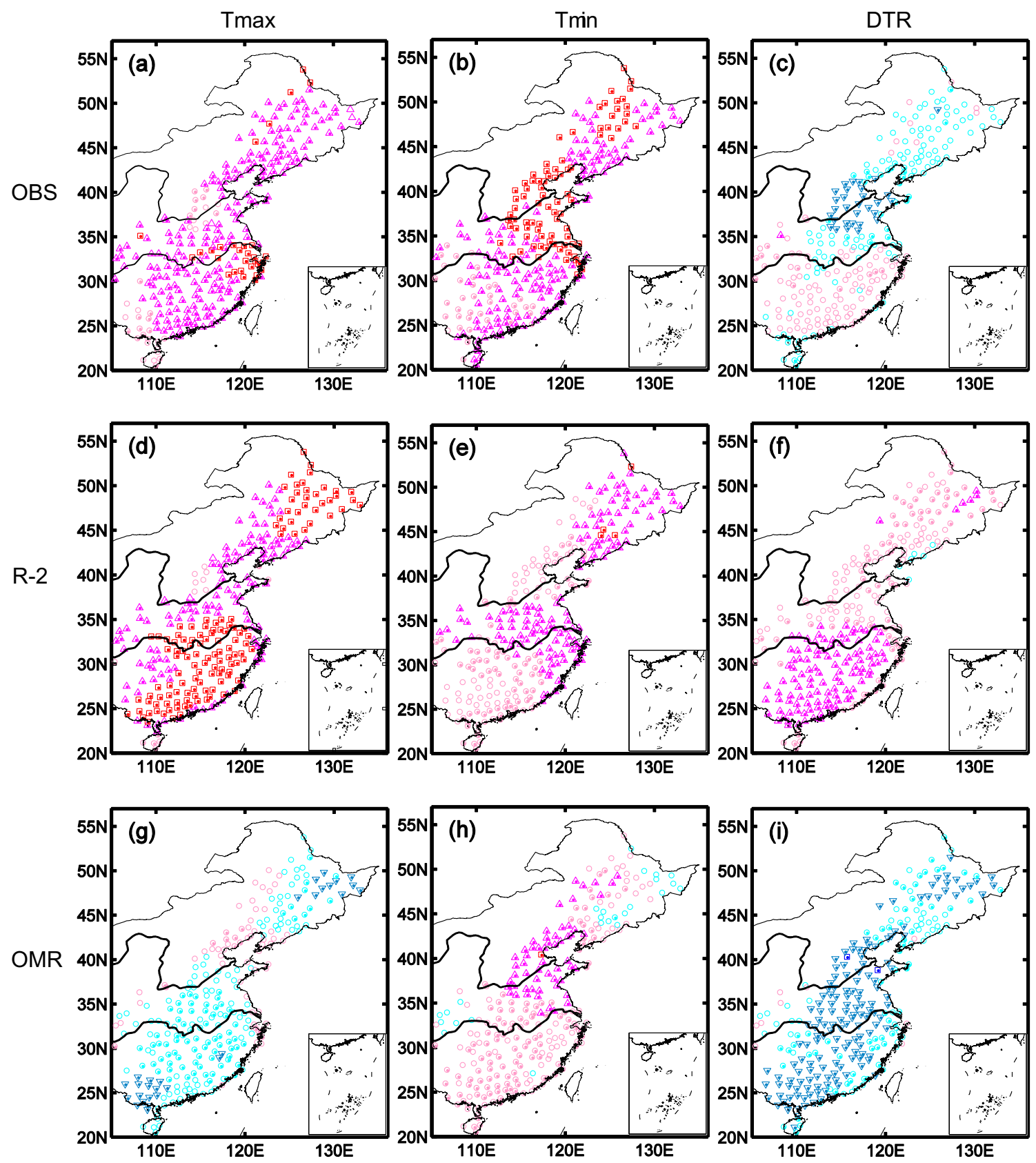

\section{$\square-0.9--0.6 \quad \nabla-0.6--0.3$}

Fig. 3 Linear trends in annual Tmax (left column), Tmin (middle column), and diurnal temperature range (DTR; right column) from observation (upper row), R-2 (middle row), and observation minus
-0.3-0 $\bigcirc-0.3 \triangle 0.3-0.6 \square 0.6-0.9$

reanalysis (OMR; bottom row) for the period 1979-2008. The units are ${ }^{\circ} \mathrm{C}$ decade ${ }^{-1}$. Symbols with a dot inside denote that the trend is statistically significant $(p<0.05)$ on global solar radiation data from radiation measurements in China (e.g., Qian et al. 2007, 2011a). However, R-2 shows a more apparent solar dimming to brightening result, as evidenced from the EEMD nonlinear trend (Fig. 4). The linear trend in R-2 DTR after 1990 is $0.498{ }^{\circ} \mathrm{C}$ decade $^{-1}$, which is statistically significant at the $1 \%$ level, making the overall linear trend in the entire 30-year period significantly increase by $0.259{ }^{\circ} \mathrm{C}$ decade $^{-1}$ (Table 1 ). In contrast, the OMR trend in DTR reveals an overall decreasing trend, with an accelerated rate after 1990. Therefore, the overall effect of LULCC is significant (Table 1) reduction in SSR over the entire 30year period, resulting in a negative radiative forcing that offset 


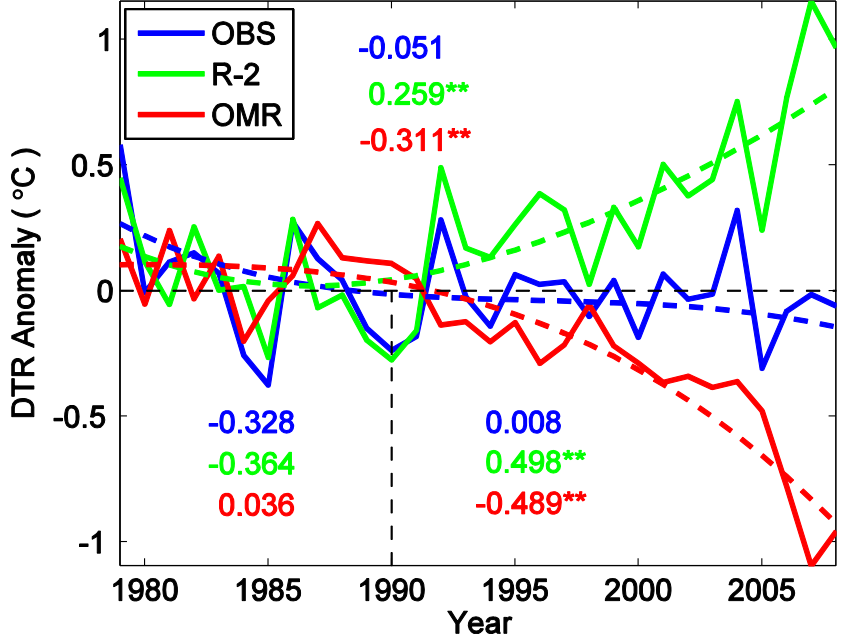

Fig. 4 Eastern China area mean annual diurnal temperature range (DTR) anomalies (solid lines) estimated from observation, R-2, and observation minus reanalysis (OMR) for the period 1979-2008, along with their nonlinear trends (dashed lines) estimated from the EEMD method. The anomalies from R-2 and OMR were calculated relative to the mean of the first 10 years of observation. The figures in the upper half indicate the linear trend coefficients $\left({ }^{\circ} \mathrm{C}\right.$ decade $\left.{ }^{-1}\right)$ estimated over the entire 30 -year period; those in the lower half indicate the linear trend coefficients estimated for the periods 1979-1989 and 1990-2008. * (**)Denotes that the linear trend is statistically significant at $p<0.05(0.01)$

a large part of the positive radiative forcing induced by other factors in the R-2.

\subsection{Trends in SSR during 1990-2008}

Many studies in China have reported the transition in SSR from decreasing trend to a leveling off in 1990 (e.g., Liu et al. 2004; Che et al. 2005; Qian et al. 2006, 2011a; Shi et al. 2008), which is also evident in Fig. 4. Therefore, in this section, we examine the spatial distribution of trends in SSR and the role

Table 1 Linear trends and their $95 \%$ confidence intervals in eastern China area mean annual Tmax, Tmin, and DTR from observation (OBS), reanalysis (R-2), and their differences (OMR) for the periods 1979-2008 and 1990-2008

\begin{tabular}{|c|c|c|c|}
\hline \multirow[t]{2}{*}{ Variables } & \multirow[t]{2}{*}{ Items } & \multicolumn{2}{|c|}{ Trend in ${ }^{\circ} \mathrm{C}$ decade ${ }^{-1}$} \\
\hline & & 1979-2008 & 1990-2008 \\
\hline \multirow[t]{3}{*}{ Tmax } & OBS & $0.448 \pm 0.149^{* *}$ & $0.475 \pm 0.278^{* *}$ \\
\hline & $\mathrm{R}-2$ & $0.569 \pm 0.172 * *$ & $0.725 \pm 0.314^{* *}$ \\
\hline & OMR & $-0.122 \pm 0.07 * *$ & $-0.25 \pm 0.117^{* *}$ \\
\hline \multirow[t]{3}{*}{ Tmin } & OBS & $0.499 \pm 0.123 * *$ & $0.467 \pm 0.285^{* *}$ \\
\hline & $\mathrm{R}-2$ & $0.31 \pm 0.141 * *$ & $0.228 \pm 0.305$ \\
\hline & OMR & $0.189 \pm 0.047 * *$ & $0.239 \pm 0.097 * *$ \\
\hline \multirow[t]{3}{*}{ DTR } & OBS & $-0.051 \pm 0.086$ & $0.008 \pm 0.142$ \\
\hline & $\mathrm{R}-2$ & $0.259 \pm 0.115^{* *}$ & $0.498 \pm 0.202 * *$ \\
\hline & OMR & $-0.311 \pm 0.08 * *$ & $-0.489 \pm 0.139 * *$ \\
\hline
\end{tabular}

* (**)Denotes that a trend is statistically significant at the $5 \%(1 \%)$ level of LULCC for the period 1990-2008 in greater detail. Figure 5a shows that during this period, the observed trend in DTR in our research domain shows a sandwich pattern, i.e., a slight increasing trend in northeastern China and southern China south of the Yangtze River, whereas a decreasing trend in North China Plain where linear trends in many stations are statistically significant. However, in R-2, nearly all of the stations show increasing trends in SSR, indicated from both the DTR (Fig. 5b) and the downward SSR (Fig. 5c). Linear trends in more than half of the stations are statistically significant, particularly in southern China south of the Yangtze River, where the linear trends are much larger than those in other areas and are consistent in both DTR and downward SSR. The OMR trends (Fig. 5d) reveal that the effect of LULCC is decreasing the SSR at most stations, particularly in North China Plain and southern China, where linear trends are statistically significant at nearly all stations. Because the brightening effect in the R-2 induced by other factors is larger in southern China than that in North China Plain (Fig. 5b, c); the dimming effect of LULCC (Fig. 5d) cannot fully offset other brightening effects (Fig. 5b, c) in that region, thus resulting in slightly brightening trends at most stations in this area in the observation (Fig. 5a). In contrast, the dimming effect of LULCC exceeds other brightening effects in North China Plain, thus resulting in dimming trends in that region. Overall, the effects of LULCC on SSR, Tmax, and Tmin are all stronger after 1990 than those during the entire 30-year period (Table 1). This result is reasonable because the reform and opening-up process accelerated after Comrade Deng Xiaoping's speech during his inspection tour to southern China in early 1992.

\section{Discussion}

The dimming impact of LULCC on SSR in eastern China reported in this study (Figs. 3i, 4, and 5d) may be partly associated with urbanization-related increasing anthropogenic aerosol concentrations by pollutant emission, which is a biogeochemical effect of LULCC. Alpert and Kishcha (2008) had shown that solar dimming was observed over only a limited part of the total land area and was restricted to highly populated sites dominated by anthropogenic aerosol emissions and that urban areas received less solar radiation than rural areas. $\mathrm{Wu}$ et al. (2012) reported decreasing trends in visibility at most stations in China in recent 50 years and visibility in large cities is lower than small cities. Significantly increased aerosol concentrations by pollutant emission in eastern China for the last few decades have been reported (e.g., Qian et al. 2009b) and have been suggested to be responsible for the observed reduction in global solar radiation (Qian et al. 2007). Ren and Zhou (2014) showed that the urbanization effect significantly reduced DTR in China by comparing urban sites to rural sites, 
Fig. 5 Linear trends in annual surface solar radiation estimated from a observational DTR, b R-2 DTR, c R-2 downward solar radiation flux at the surface, and $\mathbf{d}$ observation minus reanalysis (OMR) DTR for the period 1990-2008. In a, b, and d, the units are ${ }^{\circ} \mathrm{C}$ decade ${ }^{-1}$; those in $\mathbf{c}$ are $\mathrm{W} \mathrm{m}^{-2}$ decade $^{-1}$. Symbols with a dot inside denote that the trend is statistically significant $(p<0.05)$ (a) OBS DTR

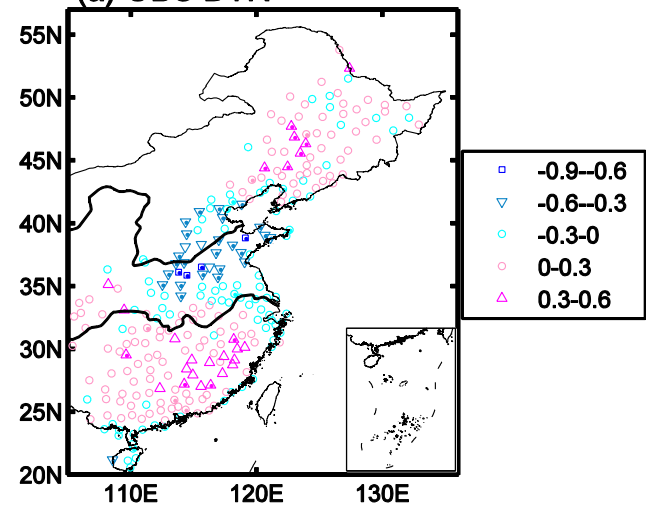

(c) R-2 Downward SSR

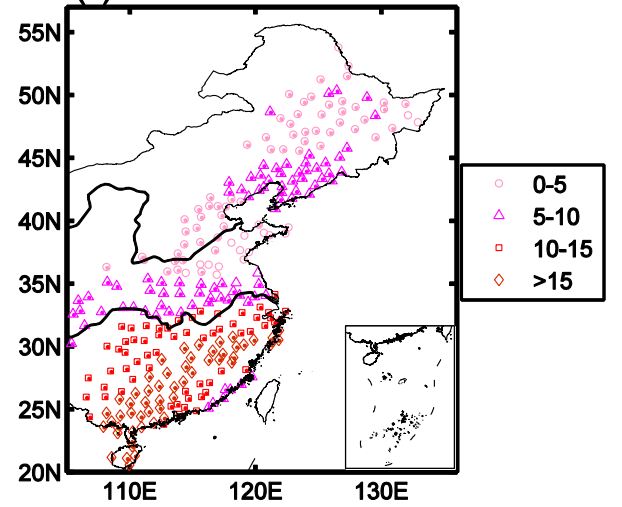

(b) R-2 DTR

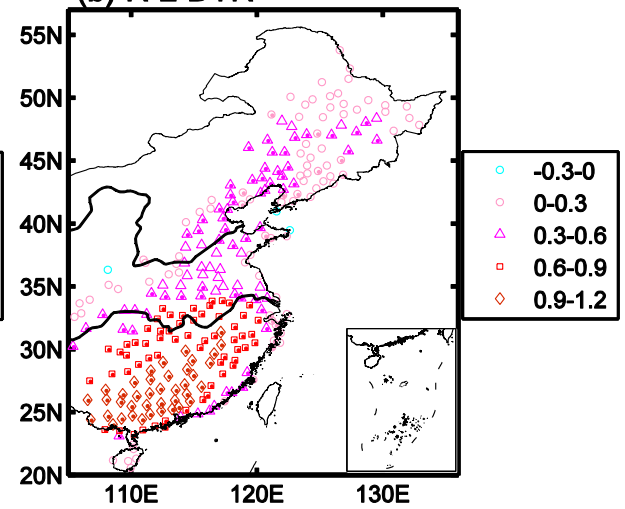

(d) OMR DTR

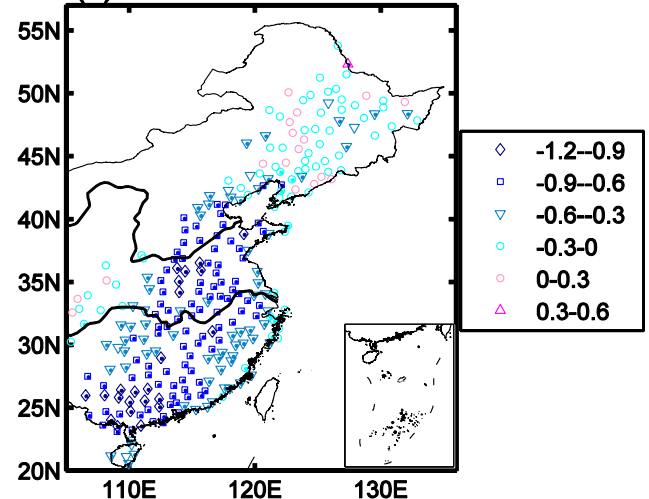

which were chosen from ordinary meteorological stations based on population. Other LULCC, such as the expansion of agricultural irrigated land in Henan and Shandong Province, may also reduce SSR through increasing cloud cover (Lobell et al. 2006) or water vapor (Douglas et al. 2006) in the daytime by biogeophysical processes. It should be noted that the observed change in cloud cover is a result of many factors. Hua and Chen (2013) conducted sensitivity simulations with potential land cover and with current land use in the NCAR Community Atmosphere Model (CAM4.0) to show that LULCC significantly reduced the DTR in eastern China. The dimming impacts of LULCC on SSR will eventually cool Tmax (Fig. 3g). On the contrary, the impact of LULCC on Tmin may be mainly through urbanization biogeophysical effects, as indicated by Fig. 3h, which shows that the largest warming is located in North China Plain. Ren and Zhou (2014) showed that urbanization effects in China are more apparent for Tmin in North China Plain. These urbanization effects may be related mainly to the heat release from the urban infrastructure during the night. Overall, the impact of LULCC on Tmax and Tmin are different and thus need to be examined separately.

The brightening in the reanalysis after 1990 (Fig. 5b, c) is important to the transition in the observed SSR. This brightening could be partly from the decreasing in total cloud cover especially in southern China in the reanalysis (Fig. 6), although before 1990 changes in cloud cover made negligible contribution to the dimming (Qian et al. 2006; Norris and Wild 2009). Norris and Wild (2009) has also noted that between 1990 and 2002, the observed surface solar flux increased by a nonsignificant $4 \mathrm{~W} \mathrm{~m}^{-2}$ decade $^{-1}$ over eastern China, half of which can be attributed to a reduction in

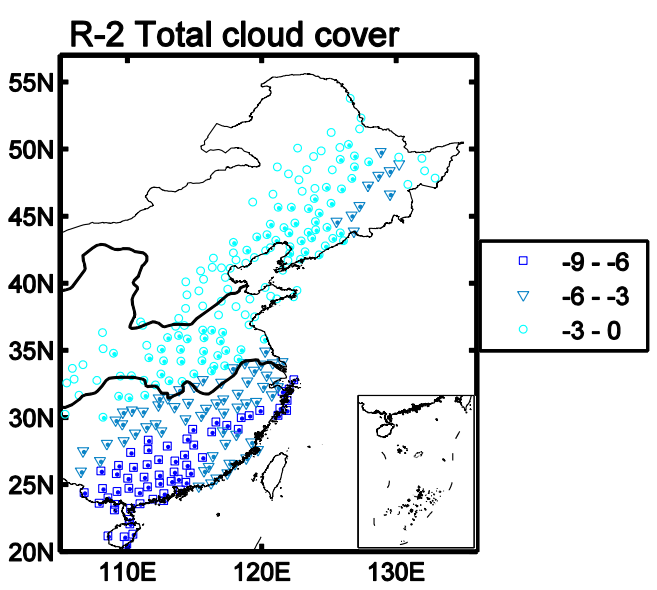

Fig. 6 Linear trends in annual total cloud cover (at entire atmosphere considered as a single layer) in the reanalysis for the period 1990-2008. The units are $\%$ decade ${ }^{-1}$. Symbols with a dot inside indicate the trend is statistically significant 
cloud cover. Other factors could also be possible and deserve further investigation.

The uncertainties in the reanalysis data due to the assimilation methods and models have been largely reduced in this study. First, the most important change in the assimilation was the introduction of satellite observing systems in December 1978, which could result in a spurious jump in the climatology. However, this is not a problem in this study, which focuses on a period after 1979. Moreover, systematic bias between the reanalysis and observation has been reduced by comparing anomalies in this study. Second, the OMR method proposed by Kalnay and Cai (2003) is based on the assumption that surface observations are not being used in the reanalysis, therefore, not all reanalysis datasets are suitable using this method. R-2, which is used in this study, is designed to improve upon the NCEP/NCAR reanalysis used in the data of Kalnay and Cai (2003) by fixing the errors and by updating the parameterizations of the physical processes. Admittedly, it is not possible to definitively attribute the OMR differences solely to the near-surface forcings (Kalnay et al. 2006). The results obtained in this study are much more illustrative rather than definitive.

\section{Conclusions}

In this study, we have examined the role of LULCC on changes in SSR in eastern China for the periods 1979-2008 and 1990-2008 by using homogeneous temperature data and by applying OMR approach from a surface solar energy perspective. The main findings are summarized in the following points:

1. For the period 1979-2008, the impact of LULCC was a reduction in SSR at most stations in eastern China, whereas SSR in R-2 showed increases at nearly all stations. The competition of the dimming effect of LULCC with the brightening effect in R-2 resulted in the observed dipole pattern of SSR, with slightly decreasing (increasing) trends in most stations north (south) of the Yangtze River and statistically significant decreasing trends in North China Plain. In terms of eastern China area mean, this competition resulted in a slightly decreasing trend (dimming) in the observed SSR during the entire 30-year period, although a transition from an apparent decreasing trend to a general leveling off was identified near 1990.

2. Over the same period, both the observed Tmax and Tmin showed warming in eastern China, where the impact of LULCC cooled the Tmax but warmed the Tmin at most stations.

3. For the period 1990-2008, LULCC significantly reduced SSR in North China Plain and southern China. This dimming effect competed with the apparent brightening effect in R-2, resulting in a general leveling off in the observed SSR in terms of the eastern China area mean and a sandwich spatial pattern in the observed SSR in eastern China in which parts of North China Plain showed significant dimming. This could explain to some extent the leveling off in the observed SSR since 1990 as referred to in the Introduction at least in eastern China.

Acknowledgments This research was sponsored by the National Basic Research Program of China (Grant 2011CB952003) and the Jiangsu Collaborative Innovation Center for Climate Change. The author would like to thank two anonymous reviewers for their helpful suggestions.

Open Access This article is distributed under the terms of the Creative Commons Attribution License which permits any use, distribution, and reproduction in any medium, provided the original author(s) and the source are credited.

\section{References}

Allen RJ, Norris JR, Wild M (2013) Evaluation of multidecadal variability in CMIP5 surface solar radiation and inferred underestimation of aerosol direct effects over Europe, China, Japan, and India. J Geophys Res Atmos 118:6311-6336. doi:10.1002/jgrd.50426

Alpert P, Kishcha P (2008) Quantification of the effect of urbanization on solar dimming. Geophys Res Lett 35, L08801. doi:10.1029/ 2007GL033012

Alpert P, Kishcha P, Kaufman YJ, Schwarzbard R (2005) Global dimming or local dimming? Effect of urbanization on sunlight availability. Geophys Res Lett 32, L17802 . doi:10.1029/2005GL023320

Bristow KL, Campbell S (1984) On the relationship between incoming solar radiation and daily maximum and minimum temperature. Agric For Meteorol 31:159-166. doi:10.1016/0168-1923(84) 90017-0

Cai M, Kalnay E (2004) Reply, climate (communication arising): impact of land-use change on climate. Nature 427:214

Che HZ, Shi GY, Zhang XY, Arimoto R, Zhao JQ, Xu L, Wang B, Chen ZH (2005) Analysis of 40 years of solar radiation data from China, 1961-2000. Geophys Res Lett 32, L06803. doi:10.1029/ 2004GL022322

Douglas EM, Niyogi D, Frolking S, Yeluripati JB, Pielke RA Sr, Niyogi N, Vörösmarty CJ, Mohanty UC (2006) Changes in moisture and energy fluxes due to agricultural land use and irrigation in the Indian Monsoon Belt. Geophys Res Lett 33, L14403. doi:10.1029/ 2006GL026550

Gallo KP, Easterling DR, Peterson TC (1996) The influence of land use/ land cover on climatological values of the diurnal temperature range. J Clim 9:2941-2944

$\mathrm{Hu}$ Y, Dong W, He Y (2010) Impact of land surface forcings on mean and extreme temperature in eastern China. J Geophys Res 115, D19117. doi:10.1029/2009JD013368

Hua WJ, Chen HS (2013) Impacts of regional-scale land use/land cover change on diurnal temperature range. Adv Clim Chang Res 4(3), doi: 10.3724/SP.J.1248.2013.166

Huang NE, Wu Z (2008) A review on Hilbert-Huang transform: method and its applications to geophysical studies. Rev Geophys 46, RG2006. doi:10.1029/2007RG000228

Ju JH, Qian C, Cao J (2005) The intra-seasonal oscillation of East Asian summer monsoon. Chin J Atmos Sci 29(2):187-194 (in Chinese)

Kalnay E, Cai M (2003) Impact of urbanization and land-use change on climate. Nature 423:528-531. doi:10.1038/nature01675 
Kalnay E, Cai M, Li H, Tobin J (2006) Estimation of the impact of landsurface forcings on temperature trends in eastern United States. J Geophys Res 111, D06106. doi:10.1029/2005JD006555

Kanamitsu M, Ebisuzaki W, Woollen J, Yang S-K, Hnilo JJ, Fiorino M, Potter GL (2002) NCEP-DOE AMIP-II reanalysis (R-2). Bull Am Meteorol Soc 83(11):1631-1643

Kistler R, Kalnay E, Collins W et al (2001) The NCEP/NCAR 50-year reanalysis. Bull Am Meteorol Soc 82:247-267

Li Z, Yan ZW (2009) Homogenized daily mean/maximum/ minimumtemperature series for China from1960-2008. Atmos Ocean Sci Lett 2:237-243

Li Q, Li W, Si P, Gao X, Dong W, Jones P, Huang J, Cao L (2010) Assessment of surface air warming in northeast China, with emphasis on the impacts of urbanization. Theor Appl Climatol 99:469-478

Liu B, Xu M, Henderson M, Qi Y, Li Y (2004) Taking China's temperature: daily range, warming trends, and regional variations, 19552000. J Clim 17:4453-4462

Lobell DB, Bala G, Duffy PB (2006) Biogeophysical impacts of cropland management changes on climate. Geophys Res Lett 33, L06708. doi:10.1029/2005GL025492

Mahmood R, Pielke RA Sr, Hubbard KG et al (2010) Impacts of land use land cover change on climate and future research priorities. Bull Am Meteorol Soc 91:37-46. doi:10.1175/2009BAMS2769.1

Norris JR, Wild M (2009) Trends in aerosol radiative effects over China and Japan inferred from observed cloud cover, solar "dimming," and solar "brightening". J Geophys Res 114, D00D15. doi:10.1029/ 2008JD011378

Pielke RA Sr, Pitman A, Niyogi D, Mahmood R, McAlpine C, Hossain F, Goldewijk KK, Nair U, Betts R, Fall S, Reichstein M, Kabat P, Noblet N (2011) Land use/land cover changes and climate: modeling analysis and observational evidence. WIREs Clim Chang 2: 828-850. doi:10.1002/wcc.144

Qian Y, Kaiser DP, Leung LR, Xu M (2006) More frequent cloud-free sky and less surface solar radiation in China from 1955 to 2000. Geophys Res Lett 33, L01812. doi:10.1029/2005GL024586

Qian Y, Wang W, Leung LR, Kaiser DP (2007) Variability of solar radiation under cloud-free skies in China: the role of aerosols. Geophys Res Lett 34, L12804. doi:10.1029/2006GL028800

Qian C, Fu C, Wu Z, Yan Z (2009a) On the secular change of spring onset at Stockholm. Geophys Res Lett 36, L12706. doi:10.1029/ 2009GL038617

Qian Y, Gong D, Fan J, Leung LR, Bennartz R, Chen D, Wang W (2009b) Heavy pollution suppresses light rain in China: observations and modeling. J Geophys Res 114, D00K02. doi:10.1029/ 2008JD011575

Qian C, Fu C, Wu Z (2011a) Changes in the amplitude of the temperature annual cycle in China and their implication for climate change research. J Clim 24(20):5292-5302
Qian C, Yan ZW, Wu Z, Fu CB, Tu K (2011b) Trends in temperature extremes in association with weather-intraseasonal fluctuations in eastern China. Adv Atmos Sci 28(2):297-309. doi:10.1007/s00376010-9242-9

Ren G, Zhou Y (2014) Urbanization effect on trends of extreme temperature indices of national stations over Mainland China, 1961-2008. J Clim 27:2340-2360

Shi G-Y, Hayasaka T, Ohmura A, Chen Z-H, Wang B, Zhao J-Q, Che H$\mathrm{Z}, \mathrm{Xu} \mathrm{L}$ (2008) Data quality assessment and the long-term trend of ground solar radiation in China. J Appl Meteorol Climatol 47:10061016

Streets DG, Yu C, Wu Y, Chin M, Zhao Z, Hayasaka T, Shi G (2008) Aerosol trends over China, 1980-2000. Atmos Res 88:174-182

Tang W-J, Yang K, Qin J, Cheng CCK, He J (2011) Solar radiation trend across China in recent decades: a revisit with quality-controlled data. Atmos Chem Phys 11:393-406. doi:10.5194/acp-11-393-2011

Wang KC, Dickinson RE (2013) Contribution of solar radiation to decadal temperature variability over land. Proc Natl Acad Sci U S A 110(37):14877-14882

Wild M (2009a) Global dimming and brightening: a review. J Geophys Res 114, D00D16. doi:10.1029/2008JD011470

Wild M (2009b) How well do IPCC-AR4/CMIP3 climate models simulate global dimming/brightening and twentiethcentury daytime and nighttime warming? J Geophys Res 114, D00D11. doi:10.1029/ 2008JD011372

Wild M (2012) Enlightening global dimming and brightening. Bull Am Meteorol Soc 93:27-37

Wild M, Gilgen H, Roesch A, Ohmura A, Long CN, Dutton EG, Forgan B, Kallis A, Russak V, Tsvetkov A (2005) From dimming to brightening: decadal changes in solar radiation at earth's surface. Science 308:847-850

Willson RC, Mordvinov AV (2003) Secular total solar irradiance trend during solar cycles 21-23. Geophys Res Lett 30(5):1199. doi:10. 1029/2002GL016038

Wu Z, Huang NE (2009) Ensemble empirical mode decomposition: a noise-assisted data analysis method. Adv Adapt Data Anal 1:1-41

Wu Z, Huang NE, Long SR, Peng C-K (2007) On the trend, detrending, and variability of nonlinear and nonstationary time series. Proc Natl Acad Sci U S A 104(38):14889-14894

Wu Z, Huang NE, Wallace JM, Smoliak BV, Chen X (2011) On the timevarying trend in global-mean surface temperature. Clim Dyn 37: $759-773$

Wu J, Fu C, Zhang L, Tang J (2012) Trends of visibility on sunny days in China in the recent 50 years. Atmos Environ 55:339-346

Zhou L, Dickinson RE, Tian Y, Fang J, Li Q, Kaufmann RK, Tucker CJ, Myneni RB (2004) Evidence for a significant urbanization effect on climate in China. Proc Natl Acad Sci U S A 101(26):9540-9544. doi:10.1073/pnas.0400357101 